\title{
Psicologia e internacionalização: notas críticas para pensar hierarquias Norte-Sul'
}

\author{
Leny Sato ${ }^{a *}$ (i) \\ Henrique Caetano Nardi \\ a Instituto de Psicologia, Universidade de São Paulo. São Paulo, SP, Brasil \\ ${ }^{b}$ Departamento de Psicologia Social e Institucional, Universidade Federal do Rio Grande do Sul. Porto Alegre, RS, Brasil
}

\begin{abstract}
Resumo: $\mathrm{O}$ objetivo deste artigo é promover o debate sobre as políticas de internacionalização, levando em conta as diferentes psicologias presentes no Brasil e no mundo e a relação que se estabelece entre os conhecimentos produzidos nos países do norte e os produzidos nos países do sul. Destaca-se nesse debate os elementos críticos sobre as assimetrias Norte-Sul na política de internacionalização. Para tanto, recorremos à contribuição de leituras pós-coloniais e descoloniais.
\end{abstract}

Palavras-chave: internacionalização, psicologia, relação Norte-Sul, política, Brasil.

\section{Introdução}

O objetivo deste artigo é contribuir para o debate sobre as políticas de internacionalização no âmbito da política de ciência e tecnologia, levando em conta as diferentes psicologias presente no Brasil e no mundo e a relação que se estabelece entre os conhecimentos produzidos nos países do Norte e os produzidos nos países do Sul. Destaca-se nesse debate os elementos críticos sobre possíveis assimetrias Norte-Sul na política de internacionalização. Para tanto, recorremos à contribuição de leituras pós-coloniais e descoloniais ${ }^{2}$.

Cremos que a reflexão sobre a política de ciência e tecnologia deve levar em conta a situação na qual a ciência foi colocada nesse governo. Nunca, desde a organização de nosso sistema de pós graduação, a ciência teve tão pouco prestígio político, com cortes orçamentários e constantes ameaças de extinção e fusão de órgãos que definem e implementam a política de ciência e tecnologia no Brasil.

* Endereço para correspondência: lenysato@usp.br

1 Cabe destacar que muitas das reflexões trazidas aqui são elaborações da Comissão de Internacionalização da Associação Nacional de Pesquisa e Pós-graduação em Psicologia (Anpepp) no biênio 2016-2018, composta por Arrilton Araújo (Universidade Federal do Rio Grande do Norte - UFRN), Henrique Caetano Nardi (Universidade Federal do Rio Grande do Sul UFRGS) (coordenador) e Leny Sato (Universidade de São Paulo - USP), com a participação de Lupicínio Iñiguez-Rueda (Universidade Autônoma de Barcelona - UAB, Espanha) e Mario Pecheny (Universidade de Buenos Aires - UBA, Argentina). Essas reflexões se deram no fórum promovido durante o evento da Anpepp de 2018 e também são fruto de elaboração para apresentação de Leny Sato em mesa-redonda proposta pela Anpepp para a Reunião Anual da Sociedade Brasileira para o Progresso da Ciência (SBPC) de 2019 (Campo Grande, MS). Uma versão modificada deste artigo foi apresentada por Leny Sato na mesa-redonda "Realidade, presente e o futuro da pós-graduação: impactos e internacionalização”, no VI Seminário Novos Horizontes, cujo tema foi "Ciência, sustentabilidade e democracia: horizontes da política científica no Brasil”, promovido pela Anpepp e pela Coordenação de Aperfeiçoamento de Pessoal de Nível Superior (Capes), em 28 e 29 de novembro de 2019, em Belo Horizonte, MG.
O obscurantismo tem dominado a visão sobre o que é conhecimento, ameaçando o patrimônio construído pela ciência brasileira e penalizando a comunidade científica, a qual é avaliada a partir de uma série de preconceitos alimentados por um moralismo fortemente influenciado por perspectivas religiosas. Professores, universidades públicas e o sistema de pós-graduação e a pesquisa estão sendo frontalmente ameaçados.

Para pensar a ou as políticas de internacionalização, neste cenário de cortes severos que ameaçam décadas de construção de um sistema científico nacional, é importante propormos uma definição de política. Assim, inspirados em Michel Foucault $(1976,1994)$, podemos definir política como o conjunto das estratégias de direção da conduta que são o resultado do jogo de forças que configura as relações de poder em uma sociedade e, no caso em análise,

2 Há um debate não resolvido em torno do uso do termo descolonial ou decolonial. Para um detalhamento desse debate, ver o artigo de Pedro Pablo Gómez (2015). Aqui escolhemos o termo descolonial, pois não segue a lógica da aproximação com o termo tal qual ele é usado em inglês, ainda, cabe lembrar que decolonial é um neologismo em português. Não acreditamos que descolonial se confunda com a ideia de descolonização (outro conceito), assim acreditamos que ao usar a grafia da palavra original em português nos aproximamos mais da corrente teórica descolonial. Quanto às diferenças e aproximações entre os conceitos de descolonial e de pós-colonial, recomendamos a leitura do segundo capítulo do livro de Dailor Sartori (2017). Basicamente o primeiro termo foi criado pelo grupo modernidade/colonialidade, constituído Catherine Walsh, Walter Mignolo, Anibal Quijano, entre outras/os, e remete à crítica da modernidade como uma época criada a partir da invasão da América no século XV e o surgimento da lógica eurocêntrica como forma de dominação colonial. Já o segundo conceito foi concebido por vários autores e autoras e cujo livro, $O$ orientalismo, de Edward Saïd é um precursor. Também realiza a crítica do eurocentrismo moderno, buscando fazer emergir as vozes subalternizadas, mas seus escritos se concentram sobre as colônias europeias do século XX. São expoentes autores e autoras como Homi Bhabha e Gayatri Spivak, entre muitas/os outras/os. Enquanto o primeiro termo centra a sua discussão na América e é influenciado pelo conceito de sistema-mundo, marcado pelo marxismo, o segundo privilegia a crítica do discurso colonial e a potencialidade de agência dos sujeitos. 
envolvendo os jogos de legitimação da verdade do discurso científico, levando em conta a diversidade epistemológica da psicologia no Brasil. Nessa perspectiva, não existe saber que brote ou paire no/do vazio - afirmá-lo é uma forma de assumir uma posição de enunciação, um posicionamento na pólis, ou seja, político, e sua legitimidade (a sua produção) depende de uma forma específica de institucionalidade, a qual se inscreve em uma estrutura/dinâmica social. Essa institucionalidade opera a partir de critérios/ procedimentos/análises que precisam ser pensados na sua especificidade brasileira, sem desconsiderar, entretanto, as formas de governamentalidade global (Lemke, 2012) que remetem às hierarquias coloniais Norte-Sul e a um mercado da produção científica (Reed-Elsevier, Sage, Taylor \& Francis-Routledge, Springer, Wiley-Blackwell, revistas predatórias; e ISI/Thomson Reuters, Scopus, indexadores, para citar algumas empresas e veículos). Esse mercado acadêmico se associa com outros mercados, por exemplo, a indústria das patentes, que alimenta a produção tecnológica e as lógicas da divisão internacional do trabalho, i.e., quem pensa e quem copia/executa no nosso caso, quem produz conceitos/modelos e quem os usa/replica/adapta (Nardi, 2017).

Além disso, no jogo avaliativo que segue a lógica dos indexadores, veremos que, no caso específico da psicologia que estamos aqui analisando, é possível afirmar que não há uma análise equitativa se considerarmos a diversidade epistemológica da área. Se concordarmos que existem pelo menos dois polos epistemológicos na psicologia - ciências "naturais" $\times$ ciências "humanas" -, apesar de esta ser uma polaridade simplificadora, ela tem indicado os vetores/direções das pesquisas. Uma análise da avaliação da área mostra que nas duas últimas décadas, ela privilegia perspectivas metodológicas sustentadas em direções teóricas que podemos classificar como positivistas/neopositivistas/funcionalistas (sustentadas por formas de legitimação estatísticas ou experimentais) em detrimento daquelas vinculadas ao materialismo/ construcionismo/pós-estruturalismo. Como a crítica das formas de produção também obedece a uma lógica colonial e linguística, há uma forte relação entre elas. No decorrer do artigo buscaremos demonstrar como ambas as questões, i.e., linguística e colonial, se associam ao privilegiar determinadas formas de internacionalização em detrimento de outras. Acreditando que essa análise faz sentido, decidimos focalizar nossa crítica na posição das psicologias mais próximas das ciências humanas e, também, apontar para as possibilidades de pensar as relações Norte-Sul de maneira não subordinada, além de apostar nas relações Sul-Sul.

\section{Notas críticas a partir da perspectiva descolonial}

O sociólogo porto-riquenho Ramón Grosfoguel (2008), apoiando-se em Mignolo e em Quijano, aponta que o tema da internacionalização estimula debates bastante ferrenhos, nos quais se destaca a crítica às diversas hierarquias globais, dentre elas:

uma hierarquia epistêmica que privilegia a cosmologia e o conhecimento ocidentais relativamente ao conhecimento e às cosmologias não-ocidentais, e institucionalizada no sistema universitário global (Mignolo, 1995, 2000; Quijano, 1991).

. . . uma hierarquia linguística entre as línguas europeias e não-europeias que privilegia a comunicação e a produção de conhecimento e de teorias por parte das primeiras, e que subalterniza as últimas exclusivamente como produtoras de folclore ou cultura, mas não de conhecimento/teoria (Mignolo 2000). (Grosfoguel, 2008, p. 123)

A perspectiva descolonial, tal qual apresentada por Grosfoguel (2008), defende que o conhecimento seja "pluriversal" e não universal, o que significa ter diversos projetos políticos/éticos/epistêmicos.

Essa linha de raciocínio aponta para a necessidade de refletirmos sobre o que estudamos (o que consideramos problema), como estudamos e quais categorias/leituras teóricas utilizamos para estudar a nossa realidade.

Alguns exemplos do campo de estudos do trabalho mostram como determinadas categorias foram criadas tomando-se como parâmetro a realidade dos países do Norte, que é distinta da observada nos países do Sul. Um primeiro exemplo vem da Organização Internacional do Trabalho (OIT), que na década de 1970 cunhou o termo "trabalho informal" para se referir à realidade de trabalho no continente africano, em países não industriais, como Quênia e Gana. Essa categorização tomou por referência o trabalho na sociedade industrial, urbana e salarial do continente europeu, denominado de "trabalho formal", o qual foi considerado como norma e como meta a ser alcançada (Sato, 2011), associado a uma determinada concepção sobre "desenvolvimento". Esse termo foi cunhado a partir de pesquisa sobre a realidade de trabalho no Quênia e em Gana conduzida por antropólogos ingleses.

A denominação "trabalho informal" é alvo de muitas críticas por parte de cientistas latino-americanos (Sato, 2011). Dentre elas, tem-se: o fato de não considerar a realidade complexa e diversa dos países do Sul, homogeneizando sob essa denominação muitas realidades de trabalho distintas; dar a conotação de que o denominado "trabalho informal" não teria forma. Ele tem, sim, forma, mas ela é construída em outros termos; trata-se de um trabalho que é institucionalizado, mas não pelo Estado, e sim pelas pessoas que constroem regras e acordos, inclusive códigos deontológicos.

Devido às críticas, alguns pesquisadores propõem a adoção de outro termo para se referir às diversas modalidades de trabalho que escapam à relação de assalariamento e que são criações enraizadas na cultura 
do lugar. Assim, o pesquisador colombiano César Giraldo (2018) emprega o termo "economia popular".

Se de um lado o termo "trabalho informal" mostra-se útil para identificarmos que são trabalhos desprotegidos e desregulados perante o Estado, de outro, ele tem pouco valor heurístico, pois tal denominação é empregada para se referir a múltiplas formas, múltiplas dinâmicas e às muitas motivações que levam a população a criá-los.

Continuando ainda com exemplos do campo de estudos da primeira autora, no mesmo sentido, Abdallah Nouroudine (2011), filósofo de União de Comores (país situado na costa oriental da África), tece críticas ao fato de adotar-se como hegemônica a concepção de trabalho estritamente europeia, mercantil e ocidental. Como aponta o autor, a realidade em seu país mostra a existência de muitas outras formas de trabalho, não remuneradas inclusive, as quais permitem a reprodução da vida social e que seguem valores culturais e solidários muito próprios. Há uma expertise, um saber-fazer e uma avaliação sobre o que é um "trabalho bem feito" a partir de critérios bastante próprios, que pouco lembram as regras de avaliação de um trabalho mercantil numa indústria ou num serviço segundo a lógica capitalista.

Para ilustrar seu entendimento de que o olhar da ciência construída no Norte é apenas um dos olhares, a pesquisadora portuguesa Inocência Mata (2014) apresenta a seguinte narrativa, na introdução de seu artigo sobre "estudos pós-coloniais". Diz ela:

Um grupo de turistas ocidentais vai visitar uma reserva em África, e a dada altura, um dos turistas ocidentais pergunta ao guia, um africano, depois de ver um animal que nunca tinha visto antes, que animal era aquele. Mas a pergunta vinha formulada assim; "como é que se chama aquele animal branco com riscos pretos?". O guia africano responde: "chama-se zebra. Mas atenção, não é um animal branco com riscos pretos. Pelo contrário, é um animal preto com riscos brancos". Entretanto, a discussão prolonga-se, não houve entendimento, com as duas partes a revelarem verdadeira frustração. O africano dizia: "Mas isto foi sempre assim, o animal é um animal preto com riscos brancos, não sei como esse senhor vem agora, ainda por cima nem sabia que animal era, vem aqui e quer obrigar-me a pensar [itálicos nossos] que o animal é branco com riscos pretos! (p. 28)

Para pensarmos a internacionalização numa relação não subordinada, é relevante refletirmos sobre em que medida nossas agendas de pesquisa não estariam sendo influenciadas por aquelas que fazem sentido às sociedades do Norte, mas não tanto à nossa sociedade. Para isso, recorremos novamente ao campo dos estudos do trabalho para pontuar que, apesar de o Brasil nunca ter sido uma sociedade salarial - ou seja, constituída massivamente pelo trabalho assalariado e protegido -, a psicologia, no Brasil, estudou prioritariamente o trabalho urbano, assalariado, regulado e protegido, a partir de referências construídas em países do Norte. Apenas recentemente a realidade do trabalho rural e as diversas modalidades de trabalho urbano criadas espontaneamente pelas pessoas fora das empresas e da relação de assalariamento - o que conhecemos como trabalho informal - têm atraído, de forma programática, a atenção da psicologia do trabalho; interessa saber como as pessoas criam trabalho (Sato, 2017).

Em relação às diferentes epistemologias, é difícil pensar o conhecimento científico fora dos padrões europeus, ocide ntais, do Norte, mas nós temos, na psicologia, um exemplo importante: a psicologia social latino-americana, que procura contemplar a singularidade dos processos no nosso contexto. Em outras disciplinas, também temos teorias que foram erguidas a partir do solo local. Por exemplo, o geógrafo brasileiro e baiano, Milton Santos, que construiu uma teoria para pensar o processo de urbanização nos países do Sul - América Latina e África -, contrapondo-se a teorias de desenvolvimento pensadas a partir da realidade do Norte. Podemos dizer que esses são exemplos do que Grosfoguel denomina de "pluriversal".

Não se trata, é claro, de praticar um tipo de xenofobia epistemológica nem de jogar o bebê com a água do banho, mas essas reflexões, muitas delas até por sua radicalidade, põem-nos a pensar sobre como fazemos nossa ciência; como podemos, nesse fazer contemplar a diversidade dos modos de se construir as psicologias?

\section{O inglês como idioma franco da ciência: implicações para as hierarquias Norte-Sul}

Outro tema relevante quando se discute a internacionalização é o idioma preferencial a ser empregado nas publicações. Ele é examinado criticamente por Rosa e Alves (2011). Os autores focalizam o tema da imposição de um idioma na relação colonial em detrimento dos idiomas locais.

A formação do campo científico "internacional" dá-se nesse contexto de relação colonial e o inglês é adotado como língua franca da ciência.

Isso significa que: 1) os países do Norte detêm o controle sobre a produção do conhecimento, que se pretende (e se torna) universal, não se restringindo às suas fronteiras territoriais; 2) "ao definir o inglês como base linguística comum, excluem-se outras línguas e o fluxo de informações entre o Norte e o Sul começa a operar em apenas um sentido normativo: do Norte para o Sul. Se o circuito global de produção de conhecimento científico opera apenas sob o idioma inglês, então se torna inviável que uma pesquisa feita em outra língua circule nesse circuito" (Rosa \& Alves, 2011, p. 256); 3) sob o domínio do idioma inglês, dá-se "a impossibilidade de o sujeito subalterno falar. Ele fica condenado a não se expressar em sua língua nativa, sendo obrigado a se mover nos limites autorizados pela estrutura 
de poder controlada pelo Norte Global, isto é, o inglês" (Rosa \& Alves, 2011, p. 256). A imposição linguística é um dos temas mais frequentemente comentados quando alguém do Sul global busca publicar em revistas que adotam o inglês, uma vez que o texto deve ser revisado por um native speaker, supondo-se que todas as pessoas que falam inglês o falam da mesma forma, apesar das muitas diferenças entre o inglês da África do Sul, da Inglaterra, do Canadá anglófono, da Nova Zelândia, da Austrália, do Quênia ou dos Estados Unidos da América, por exemplo. Desse modo, a figura do native speaker se impõe de forma universalizante, buscando apagar as hierarquias internas do inglês na sua diversidade, construída, esta também, a partir da lógica colonial. Uma língua mestiça, tal como reivindica Gloria Anzaldúa (2000), se torna um estranho objeto que a língua franca da ciência não aceita, pois exporia a sua estrutura colonial.

Sabemos que a disputa pelo controle dos Estados-Nações passa pela definição de um idioma oficial, como é, por exemplo, o caso do castelhano, na Espanha, mas numa lógica de convivência com as comunidades autônomas, nas quais o galego, o basco e o catalão têm uso oficial. Entretanto, o castelhano, segue como a língua nacional. No Brasil, sabemos, não há essa convivência os idiomas indígenas, cuja maioria foi praticamente exterminada, e falamos um idioma europeu: o português. Mas isso não se dá sem resistência, pois há menos de um ano, uma matéria sobre o tema das etnias indígenas no Brasil informou que aqui temos mais de 100 idiomas (Abdala, 2014). Mostraram-se, inclusive, algumas escolas que perseveram no ensino do idioma indígena ao lado do português. Também sabemos que por ocasião da Segunda Guerra Mundial, o ensino dos idiomas japonês, alemão e italiano foi proibido. O idioma, então, não é apenas um meio de comunicação, mas um instrumento para o exercício da dominação.

No debate sobre a internacionalização, há dois posicionamentos sobre o inglês como língua franca: de um lado, o que defende a sua hegemonia, segundo o argumento de sua "funcionalidade" e de ser, supostamente, uma "base neutra de comunicação"; e, de outro lado, a visão de que a "suposta neutralidade desse processo" não existe, dado que quando o inglês ocupa a posição de idioma hipercentral, ele empurraria os outros idiomas para a periferia (Rosa \& Alves, 2011).

Renato Ortiz (2004), cientista social brasileiro, é um dos que criticam o entendimento de o inglês ser uma "base neutra de comunicação", por considerar que essa é uma leitura ingênua presente nos estudos desenvolvidos por linguistas. David Crystall (1997, citado por Ortiz, 2004 , p. 8), entretanto, reconhece que o inglês alcançou esse espaço pelo poder militar, político e econômico do seu povo. Note-se que é bastante recente a assunção da posição do inglês como idioma hipercentral - isso ocorreu após a Segunda Guerra Mundial.

Ortiz (2004) entende ser possível adotar o inglês para construir o discurso nas ciências da natureza, porque consegue reduzir a linguagem, depurá-la de sua malha sociocultural [itálicos nossos], algo impensável quando se deseja compreender a sociedade. Nesse caso, o inglês não pode funcionar como língua franca, não por uma questão de princípio, ou de orgulho nacional, mas devido à própria natureza do saber construído. (p. 15)

Assim, adotar o inglês como língua franca nas ciências humanas impossibilita uma relação igualitária, pois a língua é essencial para construir os objetos sociais, o que está atrelado às especificidades históricas e geográficas.

No que se refere à tradução, trata-se de um trabalho que exige uma delicadeza para lidar com a complexidade, devendo transpor vários obstáculos. Assim, continua Renato Ortiz (2004):

É preciso sempre um esforço adicional de interpretação, pois nenhuma tradução é literal. Termos, conceitos e abstrações devem buscar equivalentes quando passam de um código para outro. A língua reforça o vínculo discursivo ao solo onde as ciências sociais são elaboradas [itálicos nossos]. Mas não se trata apenas de tradução direta, existem diferentes tradições, e muitas vezes vertê-las de uma língua para outra não significa simplesmente encontrar o vocábulo adequado, mas considerar toda uma constelação expressiva. (p. 15)

Por exemplo, quando afirmamos que as pessoas "se viram" para sobreviver - a "viração" - estamos nos referindo a todo um conjunto de significados muito próprios, uma expressão que está enraizada no lugar, no contexto histórico, cultural e material, que não pode ser expressa na tradução to turn around. Tal fenômeno remete ao exame que considere a sua transversalidade a vários campos de investigação, como por exemplo: psicologia do trabalho, psicologia comunitária, psicologia e políticas públicas, psicologia e o direito à cidade etc.

Renato Ortiz (2004) aponta, ainda, as diferenças do que é mais valorizado nas publicações nas ciências sociais e nas ciências exatas. Nas ciências exatas (e, talvez, também nas ciências biológicas), valorizam-se os "resultados recentes", que trazem dividendos para todo o conjunto da área, e a questão do tempo é importante. Os artigos são mais breves (em alguns casos, brevíssimos). "Informação e tempo são portanto elementos fundamentais que favorecem o uso do inglês. É necessário se exprimir de forma mais abrangente, numa duração a mais curta possível" (Ortiz, 2004, p. 16). Os dados são obtidos segundo variáveis ou códigos já padronizados na área. Em contraste, no campo das ciências sociais, o livro é veículo importante de divulgação e, quando são artigos, eles tendem a ser mais longos, de modo a apresentar a "informação" (os "dados"), que faz parte do arcabouço teórico e explicativo. E segue Ortiz (2004): 
. . sendo que, muitas vezes, esse arcabouço interpretativo é mais importante do que os dados veiculados (o que não significa dizer que a informação seja irrelevante). As ciências sociais são mais interpretativas do que informativas, requerem tempo de amadurecimento e análise. (pp. 16-17)

Também há diferenças em relação à obsolescência dos conhecimentos nas ciências sociais e nas naturais e biológicas. Por exemplo: resultados mais recentes sobre os efeitos de medicamentos, de vacinas etc. tornam obsoletos, em princípio, os resultados obtidos um pouco antes.

Com estas reflexões, não se pretende defender uma recusa radical a publicar em inglês nas ciências sociais, mas é importante identificar as implicações em fazê-lo, no sentido de pensar o que fica de fora (em termos de conteúdos e estilos narrativos) e quem fica de fora (no sentido de restringir o acesso à informação). Isso parece importante quando se pensa a inserção social especificamente o acesso à informação para a comunidade não universitária/não científica, como por exemplo os profissionais/técnicos em serviços de saúde, de educação, de assistência social etc., bem como a população em geral, que cada vez mais consulta o Google e o currículo Lattes das/os profissionais e pesquisadoras/es.

Além disso, cremos ser importante uma avaliação sistemática sobre o real alcance de nossas produções em língua inglesa. Será que somos mais lidos e citados por pesquisadores de outros países quando publicamos em inglês? Será que não haveria, de partida, uma hierarquia na valorização dos trabalhos do Norte em relação aos do Sul, independentemente do idioma no qual se publica? Será que para sermos mais lidos e citados por pesquisadores de outros países, não precisaríamos contar com coautoria de pesquisadores de centros de pesquisas do Norte?

Algo a ser notado é a busca por atrair pós-doutorandos estrangeiros, por meio de fomentos à pesquisa. Por exemplo, a Fundação de Amparo à Pesquisa do Estado de São Paulo (Fapesp) exige que editais para recrutar pós-doutorandos sejam publicados também em meios de divulgação acessíveis a estrangeiros. Essa seria uma forma de construir e estreitar laços com centros de pesquisa no exterior e, assim, facilitar a publicação em periódicos internacionais em inglês. A Fapesp participa de editais em parceria com outros países nos quais o inglês, na prática, é o idioma oficial, mesmo para atividades que venham a ocorrer no Brasil dirigidas a brasileiros. Isso porque não há previsão para pagamento de serviços de tradução, além de um dos critérios de seleção dos beneficiados com o edital, ser a fluência no inglês.

Um caminho - apontado por Ortiz (2004) que muitos de nós estamos seguindo é publicar tanto em periódicos de língua inglesa (nacionais e estrangeiros), como em periódicos de língua portuguesa, de modo a ter o resultado de nossas publicações acessíveis aos nacionais.

\section{Notas sobre as políticas de internacionalização: o PrInt como exemplo}

A política de internacionalização da Coordenação de Aperfeiçoamento de Pessoal de Nível Superior (Capes) veja-se o Programa Institucional de Internacionalização (PrInt) - tem induzido a um tipo de relação entre os pesquisadores brasileiros e os de outros países (Capes, 2018). Isso incentiva um alinhamento da psicologia brasileira ao que se faz nos países do norte político e econômico do planeta, o que implica também uma hegemonia das formas de legitimação sustentadas no modelo tradicional de ciência, privilegiando um dos polos da conformação do campo epistemológico da psicologia (aquele mais próximo das ciências biológicas: modelo experimental, neurociência, psicobiologia) em detrimento da psicologia social ou vertentes da clínica mais próximas da psicanálise. A consideração da diversidade das formas de fazer ciência em psicologia - diversidade epistemológica - sempre se apresenta como um problema a ser enfrentado na avaliação dos programas de pós-graduação pela Capes.

O edital PrInt, da Capes (2018), determina com quais países muito preferencialmente deverão ser desenvolvidos os projetos de internacionalização. De acordo com o documento, 70\% dos recursos seriam destinados a parcerias com instituições internacionais, de uma lista de 26 países, dos quais: dois são latino-americanos (Argentina e México); um é africano (África do Sul); quatro são asiáticos (Japão, China, Coréia do Sul e Índia); dois são da Oceania (Nova Zelândia e Austrália). Os países restantes são da Europa e Eurásia (Rússia) e América do Norte (Canadá e Estados Unidos da América). E 30\% dos recursos poderiam ser destinados a projetos que envolvam outros países conforme a prioridade da instituição proponente.

Por sua vez, edital do Programa de Cooperação Científica Estratégica com o Sul Global (Coopbrass), também lançado pela Capes (2019), é mais modesto em termos de aporte financeiro e contempla a relação com vários países da África, Ásia, Oceania, América do Sul e Caribe. É importante lembrar o Edital Pro-África (do Conselho Nacional de Desenvolvimento Científico e Tecnológico-CNPq), de 2006, que abriu a possibilidade de iniciar contatos com centros de pesquisa e profissionais de países do continente africano. Naquele edital, havia uma modalidade intitulada "visitas exploratórias", que disponibilizava um pequeno recurso para que pesquisadores brasileiros iniciassem contatos com pesquisadores dos países listados, de modo a iniciarem, posteriormente, projetos de pesquisa conjuntos (Capes, 2019). Com o apoio desse edital, em visita a República de Cabo Verde e a Guiné-Bissau - países não industriais -, a primeira autora deste texto teve a convicção de que nunca mais poderia ministrar aulas sobre trabalho como fizera até então, pois o contato com essa região do Sul trouxera uma infinidade de conhecimentos e 
argumentos que traziam indagações aos conhecimentos do Norte, bastante presentes na nossa formação, e que muitas vezes tomamos como universais. Concluiu que nunca mais poderia pensar o trabalho na realidade brasileira sem pensar as semelhanças com a realidade no continente africano.

Uma política de internacionalização mais voltada para o vetor sul-norte tende a desvalorizar a especificidade da produção brasileira, a diversidade epistemológica e a interdisciplinaridade quando esta se aproxima das ciências humanas.

Cabe lembrar que há resistências aos modelos de avaliação/classificação contemporâneos que se sustentam na produtividade e nas citações e têm guiado em parte a avaliação conduzida no Brasil. Há críticas estatísticas (Adler, Erwing, \& Taylor 2008) quanto aos modelos que medem as citações (o impacto); há também muitas críticas à lógica chamada produtivista, a qual, além de dificultar o amadurecimento da reflexão com publicação de artigos mais robustos também incitaria ao fatiamento das publicações, a chamada salami science.

Também, a partir de um questionamento ao modelo produtivista e buscando descrever os processos que marcam a produção acadêmica no neoliberalismo, Yvona Lincoln (2012), por exemplo, analisa a economia política das publicações no plano internacional identificando três processos ligados à governamentalização neoliberal: (1) transformação da pesquisa e da publicação em commodities - lógica do financiamento e parcerias com a iniciativa privada (patentes); (2) furor avaliativo (culture of accountability); (c) produção de um regime de ranqueamento, criando hierarquias do saber. $\mathrm{O}$ resultado desses processos seria a produção de pesquisadoras/ es empreendedoras/es de si mesmas/os, gestoras/es de pesquisa, não fugindo à lógica de subjetivação neoliberal (Foucault, 2004). Segundo a autora, esses processos têm levado progressivamente a uma deslegitimação, sobretudo da pesquisa qualitativa crítica, pois esta necessitaria de mais tempo para produzir análises robustas. Reconhecemos, pois, que não se pode falar em um único e melhor modo de internacionalizar a pesquisa, a formação e a produção em psicologia e há aspectos que merecem a nossa atenção.

\section{A guisa de conclusão: experiências que nos auxiliam a seguir no debate}

Algumas experiências nos permitem avançar no debate. Por exemplo, Lupicínio Iñiguez-Rueda, professor de Psicologia Social na Universidade Autônoma de Barcelona, nos relatou, no Fórum de Internacionalização no Simpósio da Anpepp (que originou, em parte, este artigo), em 2018, algumas de suas experiências com atividades de internacionalização, que demonstravam que não é com qualquer país que se considera possível construir ações de internacionalização. Por exemplo: quando ele decidiu desenvolver pesquisas no seu período sabático na Escola de Administração de Empresas de São Paulo da Fundação Getulio Vargas (Eaesp-FGV) e constatou que, para a sua instituição, a opção pelo Brasil não era valorizada, pois ela considerava que atividades de internacionalização deveriam privilegiar instituições de pesquisa no Norte. Lupicínio também relatou a sua experiência na submissão de artigo em periódico em língua inglesa, de um país do Norte, e o parecer final não recomendava a publicação de seu artigo pois considerava que o tema nele examinado focalizava um fenômeno apenas regional (da Espanha). Entretanto, ao fazer uma busca nos artigos publicados nesse periódico, ele constatou que tinham sido publicados artigos sobre temas regionais daquele país do Norte que editava o periódico. Assim, parecia que a classificação do caráter regional dos temas variava segundo fosse de um país mais periférico (mesmo sendo europeu) ou não. Também há a prática de periódicos indicarem que os textos a eles submetidos incluam em suas referências artigos já publicados nesses mesmos periódicos.

Podemos relatar a experiência da primeira autora ao participar de um congresso de estudos latino-americanos. Dele participavam muitos estadunidenses que eram latino-americanistas e na programação havia mesas-redondas nas quais os componentes eram pesquisadores exclusivamente da América Latina. Chamava a atenção a ausência de espectadores de países do Norte nessas mesas. Muitos podem ser os motivos para essa ausência, mas parece interessante pensar nesse aspecto e cabe a pergunta: o que os latino-americanos temos a falar de nossa realidade não é de grande interesse aos latino-americanistas?

As atividades de internacionalização com países do Sul (América Latina) merecem ser cultivadas. Além do mais, pode-se usar os dois idiomas oficiais nos continentes: castelhano e português; e (por que não?), também o portunhol, nossa língua mestiça (Anzaldúa, 2000).

Cremos que a discussão sobre como se dá a internacionalização tem muita relação com a sustentabilidade $^{3}$. E, para isso, é importante recuperar a proposição de Vandana Shiva (2003), filósofa, feminista e ecologista indiana, que critica a monocultura da mente para garantir a biodiversidade. Cultura aqui se refere tanto à cultura agrícola como à cultura da mente os saberes milenares dos povos. Cabe, então, pensar em que medida praticamos a sustentabilidade da cultura da mente $\mathrm{e}$ do respeito às distintas epistemologias, às contribuições das diferentes línguas e formas de usá-las, ao desenvolvermos ações de internacionalização. Finalmente, enfatizamos que nossa posição é em favor de uma internacionalização que não reforce a lógica colonial, mas incremente as relações de cooperação Sul-Sul, respeite a diversidade linguística e construa relações mais equitativas na avaliação das diferentes áreas da psicologia.

3 Sustentabilidade é um conceito que fez parte do tema do VI Seminário Novos Horizontes. 


\section{Psychology and Internationalization: critical notes for thinking North-South hierarchies}

Abstract: This article debates on Internationalization Policies, taking into account the different psychologies present in Brazil and worldwide and the relation established between the knowledge produced in the countries of the North and in the countries of the South. This debate focuses on the critical elements about North-South asymmetries in Internationalization Policy. For that, we seek support on the contributions of postcolonial and decolonial theories.

Keywords: internationalization, psychology, relations North-South, politics, Brazil.

\section{Psychologie et internationalisation : notes critiques pour penser les hiérarchies Nord-Sud}

Résumé: Cet article vise à promouvoir le débat sur les politiques d'internationalisation, en prenant compte les différentes psychologies présentes au Brésil et dans le monde, ainsi que la relation qui s'établit entre les savoirs produits dans les pays du Nord et ceux produits dans les pays du Sud. À l'intérieur de ce débat, les éléments critiques des asymétries Nord-Sud dans la politique d'internationalisation sont mis en relief. À cet effet, nous profitons de l'apport des lectures post-coloniales et décoloniales.

Mots-clés: internationalisation, psychologie, relation nord-sud, politique, Brésil.

\section{Psicología e internacionalización: notas críticas para pensar en jerarquías Norte-Sur}

Resumen: El objetivo de este artículo es promover el debate sobre las políticas de internacionalización, teniendo en cuenta las diferentes psicologías presentes en Brasil y en el mundo y la relación que se establece entre el conocimiento producido en los países del Norte y en los países del Sur. Se destacan en este debate los planteamientos críticos sobre las asimetrías Norte-Sur en la política de internacionalización. Para eso, recurrimos a la contribución de las lecturas poscoloniales y decoloniales.

Palabras clave: internacionalización, psicología, relación norte-sur, política, Brasil.

\section{Referências}

Abdala, V. (2014, 11 de dezembro). Brasil tem cinco línguas indígenas com mais de 10 mil falantes. Agência Brasil. Recuperado de https://bit.ly/2Wt5fM8

Adler, R., Ewing, J., \& Taylor, P. (2008). Joint Committee on Quantitative Assessment of Research: citation statistics: a report from the International Mathematical Union (IMU) in cooperation with the International Council of Industrial and Applied Mathematics (ICIAM) and the Institute of Mathematical Statistics (IMS). Recuperado de https://bit.ly/31QBUGO

Anzaldúa, G. (2000). Falando em línguas: uma carta para as mulheres escritoras do Terceiro Mundo (E. Marco, trad.). Revista Estudos Feministas, 8(1), 229-236.

Conselho Nacional de Desenvolvimento Científico e Tecnológico. (2016). Edital MCT/CNPq $n^{\circ}$ 016/2010: Programa de Cooperação em Ciência, Tecnologia e Inovação com Países da África: Proafrica. Recuperado de http://resultado.cnpq.br/2089098595391864

Coordenação de Aperfeiçoamento de Pessoal de Nível Superior. (2018, 2 de fevereiro). Programa Institucional de Internacionalização: Capes: PrInt: edital no. 41/2017. Diário Oficial da União. Recuperado de https://bit.ly/ 392VQT1
Coordenação de Aperfeiçoamento de Pessoal de Nível Superior. (2019). Programa de Cooperação Científica Estratégica com o Sul Global/Coopbrass: Edital no. 5/2019. Recuperado de https://bit.ly/3kQIU4Y

Foucault, M. (1976). Histoire de la sexualité: Vol. 1. : la volonté de savoir. Paris: Gallimard.

Foucault, M. (2004). Naissance de la biopolitique: cours au collège de France (1978-1979). Paris: Gallimard.

Giraldo, C. (Coord.). (2017). Economía popular desde abajo. Bogotá: Ediciones Desde Abajo.

Gómez, P. P. (2015). ¿Decolonialidad, descolonialidad o des/decolonialidad? In W. D. Mignolo \& P.P. Gómez, Trayectorias de re-existencia: ensayos en torno a la colonialidad/decolonialidad del saber, el sentir y el creer (pp. 353-362). Bogotá: Universidad Distrital Francisco Jose de Caldas.

Grosfoguel, R. (2008). Para descolonizar os estudos de economia política e os estudos pós-coloniais: transmodernidade, pensamento de fronteira e colonialidade global. Revista Crítica de Ciências Sociais, 8, 115-147.

Lemke, T. (2007). An indigestible meal? Foucault, governmentality and state theory. Distinktion: Scandinavian Journal of Social Theory, 8(2), 43-64. 
Lincoln, Y. S. (2012) The political economy of publication: Marketing, commodification, and qualitative scholarly work. Qualitative Health Research, 22(11) 1451-1459.

Mata, I. (2014). Estudos pós-coloniais. Civitas, 14(1), 27-42.

Nardi, H. C. (2017) A diversidade epistemológica e a política da pesquisa em psicologia no Brasil: a avaliação tem sido equitativa no interior da área? In M. S. Ferreira \& M. Moraes (Orgs.), Políticas de pesquisa em psicologia social (pp. 237-251). Rio de Janeiro: Nova Aliança.

Nouroudine, A. (2011). Como conhecer o trabalho quando o trabalho não é mais trabalho? Trabalho, Educação e Saúde, 9(1), 69-93.

Ortiz, R. (2004). As ciências sociais e o inglês. Revista Brasileira de Ciências Sociais, 19(54), 5-22.

Rosa, A. R., \& Alves, M. A. (2011). Pode o conhecimento em gestão e organização falar português? RAE - Revista de Administração de Empresas, 51(3), 255-264.
Sato, L. (2011). Psicologia e trabalho: focalizando as "profissões ignoradas". In B. Medrado \& W. Galindo (Orgs.), Psicologia Social e seus movimentos: 30 anos de Abrapso (pp. 233-252). Recife: Editora Universitária da UFPE.

Sato, L. (2017). Diferentes faces do trabalho no contexto urbano. In M. C. Coutinho, M. H. Bernardo, \& L. Sato (Orgs.), Psicologia social do trabalho (pp. 151-174). Petrópolis: Vozes.

Sartori, D. (2017). Pensamento descolonial e direitos indígenas: uma crítica à tese do 'marco temporal da ocupação'. Rio de Janeiro: Lumen Juris.

Shiva, V. (2003). Monoculturas da mente. São Paulo: Gaia.

Recebido: $12 / 03 / 2020$

Revisado: 27/07/2020

Aprovado: 12/11/2020 